Professor Volodymyr SYSOIEV, Dr.Sc. (Econ.)

E-mail: Sysoevvv@ukr.net

National Technical University "Kharkiv Polytechnical Institute"

Kharkiv, Ukraine

Associate Professor Yuri KUSHNERUK, PhD

E-mail: Kyshneryk_ui@ukr.net

Ivan Kozhedub Kharkov National Air Force University

Kharkiv, Ukraine

\title{
SUPPLY OPTIMIZATION MODEL IN THE HIERARCHICAL GEOGRAPHICALLY DISTRIBUTED ORGANIZATION
}

\begin{abstract}
The strategic importance of the procurement function in the large organizations management requires using effective tools by the logistics management to justify decisions in the supply process. The architecture features of hierarchical geographically distributed organizations allow the use of a hybrid supply scheme that rationally combines the advantages of centralized and decentralized purchasing and supply management (PSM). The article suggests a supply optimization model in the hierarchical geographically distributed organization (HGDO), reflecting the features of a complex, multifactorial and multi-stage procurement process. The model allows to find the optimal options for purchasing and supplying products for the criterion of minimizing the total logistics costs that characterize this process for the entire period of planning HGDO logistics support, taking into account the values of the various parameters of participants and the logistics functions of the procurement process over each period of time. The model is an effective tool for supporting and coordinating decisions made by logistics managers at different levels of management of HGDO based on numerous options for purchasing and supplying products and their budgeting in conditions of the dynamics and diversity of internal and external factors of influence.
\end{abstract}

Keywords: Purchasing and supply management, hierarchical geographically distributed organization, procurement process, centralization, decentralization, logistics costs, model, optimization.

\section{JEL Classification: C61, F62, H57, L22}

\section{Introduction}

Many large organizations (interstate, state, public, industrial) have a vertically integrated branching architecture characterized by a multi-level management system and territorially distributed structure. The main elements of 
Volodymyr Sysoiev, Yuri Kushneruk

such an architecture are the central office (CO), regional representatives (RR) and the network of territorially remote units (TRU) of the organization that are managed by interrelated goals and constraints, perform their functions in accordance with their authority and have overall funding.

A strategically important task to ensure the effective functioning of hierarchical geographically distributed organizations is the corporate procurement management, characterized by a large number and consumer diversity - a wide range of necessary material and technical resources (products), ambiguity in solving the dilemma of "centralizing or decentralizing purchasing management", the complexity of rigorous justification of the logistics decision influence on the provision of commercial and economic balance in the organization activity, objective uncertainty of efficiency estimation of supply, difficulty of logistical expenses identification (Glock and Hochrein, 2011).

The lack of a universal "recipe" for corporate procurement management of organizations of this type requires an integrated approach to solving this problem, which should unite the organizational, resource, economic and logistical aspects of the HGDO supply into a single whole. The hierarchical management structure of such organizations makes it possible to use a hybrid supply scheme that includes centralized and decentralized PSM, which is economically beneficial for the organization in whole due to coordinated actions of logistics services at different hierarchy levels, wholesale discounts, transportation savings, orders and reserves. The urgency of the problem grows in the conditions of various and dynamic conjuncture of different sales markets (foreign, national, regional, local), which significantly expands the choices of options for purchasing, delivering, handling and storing the purchased products in the HGDO supply system (Handfield and Nichols, 2004;Hesping, 2015).

The logistical nature of this problem determines its optimization character, which requires the development of economic and mathematical models that allow to increase the efficiency of using financial resources allocated for logistical support of HGDO through logistic cost minimization, taking into account changes in the procurement process parameters over time.

\section{Literature review}

The strategic importance of PSM for the different organizations activity is noted in studies by Paulrajet al. (2006) and Baier et al. (2008). Luzzini et al. (2015), Knoppen and Saenz (2015) showed the strategic role of the procurement function in creating value and competitive advantages of enterprises. Arlbjørn and Freytag (2012), Kleemannet al. (2012) investigated the features and mechanisms of public procurement.

Rozemeijer (2000) has conducted an empirical research for the study of the phenomenon of corporate advantage in purchasing. The influence of PSM on corporate sustainability was studied in the works of Miemczyket al. (2012)and 
Supply Optimization Model in the Hierarchical Geographically Distributed Organization

Giuniperoet al. (2012). Pooler et al. (2004)has shown the importance of searching for a comprehensive model of internal purchasing organization in order to use their global synergy successfully.

The centralization-decentralization issue is debated at length in the purchasing literature. Munson (2007) and Karjalainen (2011) analyzed the advantages and disadvantages of centralized and decentralized PSM for different hierarchical geographically distributed organizations. The traditional debate regarding centralized and decentralized purchasing has been supplemented by the potential benefits of mixed forms (Quintens et al., 2006) and hybrid organizational structures (Trautmann et al., 2009). Studies have indicated that most of the organizations choose hybrid purchasing scheme to manage their procurement activities (Spinaet al., 2013).

Vagstad (2000) proposed a model for investigating the impact of information on product characteristics on the choice of a centralized or decentralized approach to procurement. Rozemeijeret al.(2003) proposed to select a mechanism for coordination of purchasing management of large corporations using three constructs: purchasing maturity, corporate coherence, and business context, which allows for effectively managing purchasing synergies among individual business units of corporation. Zheng et al. (2007) conducted an analysis of research into the future of PSM based on a wide range of empirical evidence taking into account changes in sectors, types of firms, the role of people in buying and the country. Saranga and Moser (2010) evaluated the performance of purchasing and supply management using the classical and two-stage Value Chain Data Envelopment Analysis models which make use of multiple PSM measures at various stages and provide a single efficiency measure that estimates the all-round performance of a PSM function and its contribution to the long term corporate performance in various industry sectors. Pepino et al. (2012) proposed a simulation model of centralized purchasing based on Petri net for cases of serious economic suffering at the regional or national level, when the scale economies, obtainable by supply centralization, would be partly or totally compromised by the extra charges induced by the missing of contractual commitments. Balakrishnan and Natarajan (2014) suggested an integrated optimization model using integer programming that that accounts for both corporate volume discounts and divisional costs and preferences.

However, the existing models focus on separate (the functional or operational) aspects of a PSM problem (Matopoulos et al., 2016) and do not fully reflect (at the organizational and strategic level) the hybrid management mechanism taking into account the entire set of logistics functions in the supply sphere, which does not allow to optimize the procurement process for HGDO as a whole. 
Volodymyr Sysoiev, Yuri Kushneruk

\section{Description of the supply system and process}

The HGDO supply organization is implemented through a macrologistical system that includes a single procurement management system and an echelon storage system. A three-level structure of this system contains supply services and warehouses of the relevant HGDO elements at each level of the hierarchy (Figure 1). The supply services purchase the necessary products, the warehouses ones transform the material flows of purchased products in the process of their delivery to the final customers of the organization - TRU.

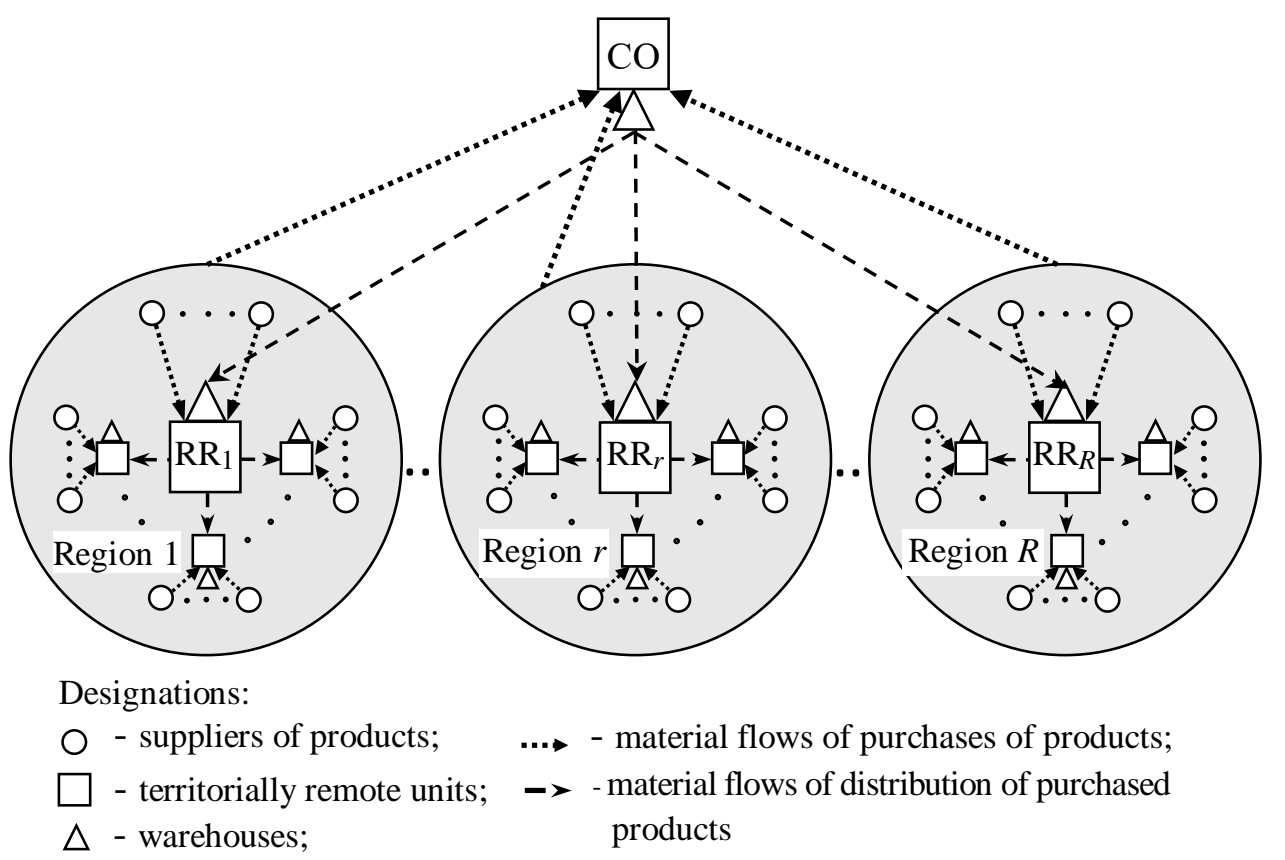

Figure 1. Scheme of the macro-logistics system and supply process in the HGDO

The main feature of PSM in this system is the interaction of its elements only vertically. This creates information asymmetry between the subordinated elements of the system, when the supply service of the higher level of the hierarchy owns complete information about the conjuncture of all markets (product nomenclature, prices, discounts, etc.) and the subdivisions of the lower levels of the organization (requirements for the nomenclature and time), which enables it to purchase the necessary products for them in the case of economic benefit, and also organize its distribution and delivery from the warehouse of the upper echelon to the warehouses of the system lower echelon. 
Supply Optimization Model in the Hierarchical Geographically Distributed Organization

On that basis all purchases of the organization can be conditionally divided into three groups:

- centralized purchasing, which are carried out by the CO;

- regional (centralized / decentralized) purchasing, which are carried out by RR for the needs of TRU located in their regions;

- decentralized purchasing of the TRU itself.

During the procurement by the supply service of the $\mathrm{CO}$, products are firstly delivered to the central warehouse $(\mathrm{CW})$, where they are processed (sorting, bundling, consolidation), temporary stored and distributed between the RR, to regional warehouses (RW) of which they are then delivered to. During the procurement by the supply service of the RR, products are firstly delivered to the $\mathrm{RW}$, where they are processed, temporarily stored and distributed among the TRU located in the given region, the local warehouses (LW) of which they are then delivered to. During the procurement by the supply service of TRU, the products are immediately delivered to its LW, where they are stored and consumed within the particular period of time.

\section{Description of the mathematical model}

To simplify the modeling of supply process in the HGDO, let's introduce the following heuristic assumptions:

- to take into account the dynamic nature of the procurement process, the planning period of logistical and maintenance support for HGDO is divided into $\mathrm{T}$ equal periods of time, within which the parameters of the supply process (the needs of the TRU, the prices for purchased products, expenses on ordering, transportation, freight processing and storage of products in the warehouses of the organization) are constant and can be changed only when moving to another time period;

- regardless of the amount of products (same type), purchased within the same period, only one order is issued and only one shipment from one supplier is performed;

- products are purchased at the beginning of each time period, therefore the costs on storing the product stock delivered to local TRU warehouses are calculated for the entire period of time;

- the costs for temporary storage of purchased products in warehouses of $\mathrm{CO}$ and RR in the process of their processing and the formation of consignments for further delivery to regional RR warehouses or the TRU local warehouses are included in the corresponding costs for cargo handling;

- to take into account the delays in deliveries caused by the processing of purchased products in the warehouses of the upper levels of the echeloned storage system, within the entire (planned) period of supply, the local 
Volodymyr Sysoiev, Yuri Kushneruk

warehouses of the TRU maintain a set level of stock reserve of each type of product, which is included in their needs and updated with each new purchase.

Let us define the basic parameters of the model:

$M$ - number of regional representations of the HGDO;

$N$ - set of territorially remote structural units of the HGDO;

$N_{m}$ - set of territorially remote structural units located in the $m$-th region, $m=$ $1, \ldots, M$, at that $\bigcup_{m=1}^{M} N_{m}=N$;

$m_{n}$ - number of the regional warehouse that serves the $n$-th structural unit, $n \in N$;

$K$ - number of types of products purchased;

$I-$ set of all suppliers;

$I_{k}$ - set of suppliers of $k$-th type products, $k=1, \ldots, K$, at that the supplier can supply more than one type of products;

$T$ - number of equal time periods to which the planned period of supply of the HGDO is divided;

$v_{k i t}$ - amount of products of type $k, k=1, \ldots, K$, available by supplier $i, i \in I_{k}$, during the period $t, t=1, \ldots, T$;

$a_{k n t}$ - demand of the consumer (TRU) $n, n \in N$, in the products of type $k, k=1, \ldots, K$, during the period $t, t=1, \ldots, T$;

$c_{\text {kit }}^{\mathrm{po}-\mathrm{c}}, c_{\text {kimt }}^{\mathrm{po}-\mathrm{r}}, c_{\text {kint }}^{\mathrm{po}-\mathrm{l}}-$ cost of placing an order for the purchase of products of type $k, k$

$=1, \ldots, K$, from the supplier $i, i \in I_{k}, \mathrm{CO}$ for the central warehouse, $m$-th RR for its regional warehouse $m, m=1, \ldots, M$, and $n$-th TRU for its local warehouse $n, n \in N$ , respectively during the period $t, t=1, \ldots, T$;

$c_{k i t}^{\mathrm{pr}}$-unit price of products of type $k, k=1, \ldots, K$, purchased from the supplier $i$, $i \in I_{k}$, during the period $t, t=1, \ldots, T$;

$c_{k i t}^{\mathrm{tr}-\mathrm{c}}, c_{k i m t}^{\mathrm{tr}-\mathrm{r}}, c_{k \text { int }}^{\mathrm{tr}-1}-$ unit transportation cost of products of type $k, k=1, \ldots, K$, from the supplier $i, i \in I_{k}$, to the central warehouse, the regional warehouse $m, m=1, \ldots, M$, and the local warehouse $n, n \in N$, respectively during the period $t, t=1, \ldots, T$;

$c_{k m t}^{\mathrm{tr}-\mathrm{cr}}-$ unit transportation cost of products of type $k, k=1, \ldots, K$, from the central warehouse to the regional warehouse $m, m=1, \ldots, M$, during the period $t, t=1, \ldots, T$; $c_{k m n t}^{\mathrm{tr}-\mathrm{rl}}-$ unit transportation cost of products of type $k, k=1, \ldots, K$, from the regional warehouse $m, m=1, \ldots, M$, to the local warehouse $n, n \in N$, during the period $t, t$ $=1, \ldots, T$;

$c_{k t}^{\mathrm{mh}-\mathrm{c}}, c_{k m t}^{\mathrm{mh}-\mathrm{r}}, c_{k n t}^{\mathrm{mh}-1}-$ unit cargo handling cost of products of type $k, k=1, \ldots, K$, in the central warehouse, the regional warehouse $m, m=1, \ldots, M$, and the local warehouse $n, n \in N$, respectively during the period $t, t=1, \ldots, T$; 
Supply Optimization Model in the Hierarchical Geographically Distributed Organization

$c_{k n t}^{\mathrm{st}-1}-$ unit storage cost of products of type $k, k=1, \ldots, K$, in the local warehouse $n$, $n \in N$, during the period $t, t=1, \ldots, T$.

Depending on the purchase volume, the price of a unit of production varies. We'll introduce the price of a product unit in the form of a system of equations:

$$
c_{k i t}^{\mathrm{pr}}=\left\{\begin{array}{l}
c_{k i t}^{\mathrm{prb}}, x_{k i t}<v_{k i t}^{\mathrm{sb}} ; \\
c_{k i t}^{\mathrm{prbb}}, v_{k i t}^{\mathrm{sb}} \leq x_{k i t} \leq v_{k i t}^{\mathrm{lb}} ; \\
c_{k i t}^{\mathrm{prlb}}, x_{k i t}>v_{k i t}^{\mathrm{lb}},
\end{array}\right.
$$

where $c_{k i t}^{\mathrm{prb}}, c_{k i t}^{\mathrm{prmb}}, c_{k i t}^{\mathrm{prlb}}$ - the price of a product unit of type $k, k=1, \ldots, K$, during purchasing respectively small (less than $v_{k i t}^{\mathrm{sb}}$ ), medium (not less than $v_{k i t}^{\mathrm{sb}}$, but not more than $v_{k i t}^{\mathrm{lb}}$ ) and in large bulk (more $v_{k i t}^{\mathrm{lb}}$ ) of products of the supplier $i, i \in I_{k}$, during the period $t, t=1, \ldots, T$.

The transportation costs for the delivery of a unit of products of type $k, k=$ $1, \ldots, K$, between the participants in the HGDO procurement process during the period $t, t=1, \ldots, T$ are calculated as:

$$
c_{k i t}^{\mathrm{tr}-\mathrm{c}}=r_{k t} d_{i-0} ; c_{k i m t}^{\mathrm{tr}-\mathrm{r}}=r_{k t} d_{i-m} ; c_{k i n t}^{\mathrm{tr}-1}=r_{k t} d_{i-n} ; c_{k m t}^{\mathrm{tr}-\mathrm{cr}}=r_{k t} d_{0-m} ; c_{k m n t}^{\mathrm{tr}-\mathrm{rl}}=r_{k t} d_{m-n},
$$

where $r_{k t}$ the transport rates for the transportation of a unit of products of type $k, k=$ $1, \ldots, K$, per $1 \mathrm{~km}$ of distance during the period $t, t=1, \ldots, T$;

$d_{i-0}, d_{i-m}, d_{i-n}, d_{0-m}, d_{m-n}-$ the distance between participants in the HGDO procurement process.

Variable parameters of the model are as follows:

$x_{k i t}^{\mathrm{c}}, x_{k i m t}^{\mathrm{r}}, x_{k i n t}^{1}$ - required amount of products of type $k, k=1, \ldots, K$, purchased from the $i$-th supplier by the $\mathrm{CO}$ for the central warehouse, $m$-th RR for its regional warehouse $m, m=1, \ldots, M$, and $n$-th TRU for its local warehouse $n, n \in N$, respectively during the period $t, t=1, \ldots, T$;

$x_{k m t}^{\text {cr }}$ - required amount of products of type $k, k=1, \ldots, K$, delivered from the central warehouse to the regional warehouse $m, m=1, \ldots, M$, during the period $t, t$ $=1, \ldots, T$;

$x_{k m n t}^{\mathrm{rl}}-$ required amount of productsof type $k, k=1, \ldots, K$, delivered from the regional warehouse $m, m=1, \ldots, M$, to the local warehouse $n, n \in N$, during the period $t, t=1, \ldots, T$; 
$C_{t}$ - funds allocated for the purchase of products at the beginning of the period $t$, $t=1, \ldots, T$

$B_{t}$ - funds remaining in the organization at the end of the period $t, t=1, \ldots, T$;

$Q_{k i t}^{\mathrm{c}}, Q_{k m i t}^{\mathrm{r}}, Q_{k n i t}^{1}-$ binary variable equal to 0 or 1 depending on the presence of the order for products of type $k, k=1, \ldots, K$, purchased from the supplier $i, i \in I_{k}$, by the CO, $m$-th RR, $m=1, \ldots, M$, and $n$-th TRU, $n \in N$, respectively during the period $t, t=1, \ldots, T$ :

$\mathrm{CO}: Q_{k i t}^{\mathrm{c}}=\left\{\begin{array}{l}1, x_{k i t}\left(x_{k i t}^{\mathrm{c}}\right)>0, \\ 0, x_{k i t}\left(x_{k i t}^{\mathrm{c}}\right)=0 ;\end{array}\right.$

$\mathrm{RR}: \quad Q_{k i m t}^{\mathrm{r}}=\left\{\begin{array}{l}1, x_{k i t}\left(x_{k i m t}^{\mathrm{r}}\right)>0 \\ 0, x_{k i t}\left(x_{k i m t}^{\mathrm{r}}\right)=0\end{array}\right.$

TRU: $\quad Q_{k n i t}^{1}=\left\{\begin{array}{l}1, x_{k i t}\left(x_{k i n t}^{1}\right)>0, \\ 0, x_{k i t}\left(x_{k i n t}^{1}\right)=0 .\end{array}\right.$

Total costs that take into account major logistics functions are determined by HGDO levels as follows:

- when purchasing products of all types, $k=1, \ldots, K$, by the $\mathrm{CO}$ for the central warehouse during the period $t$ :

$$
A_{t}^{\mathrm{c}}=\sum_{k=1}^{K}\left[\sum_{i \in I_{k}} c_{k i t}^{\mathrm{po}-\mathrm{c}} Q_{k i t}^{\mathrm{c}}+\sum_{i \in I_{k}}\left(c_{k i t}^{\mathrm{pr}}+c_{k i t}^{\mathrm{tr}-\mathrm{c}}+c_{k t}^{\mathrm{mh}-\mathrm{c}}\right) x_{k i t}^{\mathrm{c}}\right] ; t=1, \ldots, T
$$

- when purchasing products of all types $k=1, \ldots, K$, by all RR, $m=1, \ldots, M$, for its regional warehouses during the period $t$ :

$$
A_{t}^{\mathrm{r}}=\sum_{m=1}^{M} \sum_{k=1}^{K}\left[\sum_{i \in I_{k}} c_{k i m t}^{\mathrm{po}-\mathrm{r}} Q_{k i m t}^{\mathrm{r}}+\sum_{i \in I_{k}}\left(c_{k i t}^{\mathrm{pr}}+c_{k i m t}^{\mathrm{tr}-\mathrm{r}}+c_{k m t}^{\mathrm{mh}-\mathrm{r}}\right) x_{k i m t}^{\mathrm{r}}\right] ; t=1, \ldots, T ;
$$

- when purchasing products of all types $k=1, \ldots, K$, by all TRU, $n \in N$, for its local warehouse during the period $t$ :

$A_{t}^{1}=\sum_{n \in N} \sum_{k=1}^{K}\left[\sum_{i \in I_{k}} c_{k i n t}^{\mathrm{po}-1} Q_{k i n t}^{1}+\sum_{i \in I_{k}}\left(c_{k i t}^{\mathrm{pr}}+c_{k i n t}^{\mathrm{tr}-1}+c_{k n t}^{\mathrm{mh}-1}+\frac{c_{k n t}^{\mathrm{s}-1}}{2}\right) x_{k i n t}^{1}\right] ; t=1, \ldots, T ;$ 
Supply Optimization Model in the Hierarchical Geographically Distributed Organization

- when delivering products of all types, $k=1, \ldots, K$, from the central warehouse to the regional warehouse $m, m=1, \ldots, M$, during the period $t$ :

$$
D_{t}^{\mathrm{cr}}=\sum_{m=1}^{M} \sum_{k=1}^{K}\left(c_{k t}^{\mathrm{mh}-\mathrm{c}}+c_{k m t}^{\mathrm{tr}-\mathrm{cr}}+c_{k m t}^{\mathrm{mh}-\mathrm{r}}\right) x_{k m t}^{\mathrm{cr}} ; t=1, \ldots, T ;
$$

- when delivering products of all types, $k=1, \ldots, K$, from the regional warehouses, $m=1, \ldots, M$, to local warehouses, $n \in N$, during the period $t$ :

$$
D_{t}^{\mathrm{rl}}=\sum_{m=1}^{M} \sum_{n \in N} \sum_{k=1}^{K}\left(c_{k m t}^{\mathrm{mh}-\mathrm{r}}+c_{k m n t}^{\mathrm{tr}-\mathrm{rl}}++c_{k n t}^{\mathrm{mh}-1}+\frac{c_{k n t}^{\mathrm{st}-1}}{2}\right) x_{k m n t}^{\mathrm{rl}} ; t=1, \ldots, T
$$

The amount of financial resources of the organization remaining after the purchasing the products of all types at the end of period $t$ is defined as:

$$
B_{t}=C_{t}+B_{t-1}-A_{t}^{\mathrm{c}}-A_{t}^{\mathrm{r}}-A_{t}^{1}-D_{t}^{\mathrm{cr}}-D_{t}^{\mathrm{rl}} ; t=1, \ldots, T,
$$

at that $B_{0}=0$.

The complex character of the HGDO procurement process management stipulates the task formulation of its global optimization aimed at minimizing the total logistics costs on the entire planning period of logistical support as a whole in conditions of the dynamic parameters of the supply process.

Thus, the mathematical model of HGDO supply optimization for all types of products for the entire planning period of logistical support is of the form:

$$
C=\sum_{t=1}^{T} C_{t} \rightarrow \min
$$

with restrictions reflecting:

- $n$-th TRU, $n \in N$, needs satisfaction in the products of type $k, k=1, \ldots, K$, during the period $t, t=1, \ldots, T$ :

$$
\sum_{i \in I_{k}} x_{k i n t}^{1}+x_{k m_{n} n t}^{\mathrm{rl}} \geq a_{k n t}
$$

- balance relations of product flows of type $k, k=1, \ldots, K$, passing through the central warehouse of the supply system during the period $t, t=1, \ldots, T$ : 
Volodymyr Sysoiev, Yuri Kushneruk

$$
\sum_{i \in I_{k}} x_{k i t}^{\mathrm{c}} \geq \sum_{m=1}^{M} x_{k m t}^{\mathrm{cr}}
$$

- balance relations of product flows of type $k, k=1, \ldots, K$, passing through the regional warehouse $m, m=1, \ldots, M$, of the supply system during the period $t, t=1, \ldots, T$ :

$$
\sum_{i \in I_{k}} x_{k i m t}^{\mathrm{r}}+x_{k m t}^{\mathrm{cr}} \geq \sum_{n \in N_{m}} x_{k m n t}^{\mathrm{rl}} ;
$$

- the correspondence of the quantity of products of type $k, k=1, \ldots, K$, purchased by supply services of various organization elements HGDO (CO, RR, TRU) from the supplier $i, i \in I_{k}$, to its capacities during the period $t, t=1, \ldots, T$ :

$$
x_{k i t}^{\mathrm{c}}+\sum_{m=1}^{M} x_{k i m t}^{\mathrm{r}}+\sum_{n \in N} x_{k i n t}^{1} \leq v_{k i t} ;
$$

- integer and non-negativity of all controlled variables:

$$
\begin{aligned}
& x_{k i t}^{\mathrm{c}}=\left[x_{k i t}^{\mathrm{c}}\right] \geq 0 ; x_{k i m t}^{\mathrm{r}}=\left[x_{k i m t}^{\mathrm{r}}\right] \geq 0 ; x_{k i n t}^{1}=\left[x_{k i n t}^{1}\right] \geq 0 ; x_{k m t}^{\mathrm{cr}}=\left[x_{k m t}^{\mathrm{cr}}\right] \geq 0 ; \\
& x_{k m n t}^{\mathrm{rl}}=\left[x_{k m n t}^{\mathrm{rl}}\right] \geq 0 ; C_{t} \geq 0 ; B_{t} \geq 0 ; k=1, \ldots, K ; i \in I_{k} ; m=1, \ldots, M ; n \in N ; t=1, \ldots, T .
\end{aligned}
$$

To carry out the modeling of the procurement process over time, it is necessary to know the nature of changes in the parameter values characterizing the components of the process under study, or their predictive estimates. At the same time, various scenarios of possible fluctuations of certain parameters can be considered at certain time periods, reflecting the activity of HGDO elements, changing market conditions or the organization of logistics functions in the procurement process. The proposed model allows more detailed description of the parameters characterizing the logistic functions (purchase, transportation, handling and storage), which allows to take into account a wide range of factors affecting the formation of logistics costs in the modeling process.

\section{An example of application of the model}

The problem of optimizing the purchasing and supply management for a hierarchical geographically distributed organization is a hard Mixed Integer Nonlinear Programming problem with a discontinuous objective function. The 
Supply Optimization Model in the Hierarchical Geographically Distributed Organization

integer part of the problem follows from the fact that in the region of feasibility there are constraints that are given by logical conditions of the form "or - or".

We suggest to consider the application of a mathematical model for solving the formulated problem using the example of HGDO, consisting of one CO, three RR (1-3), each of which controls three TRUs (11, 12, 13, 21, 22, 23, 31, $32,33)$. To ensure the activities of the TRU, three types of products $(\mathrm{A}, \mathrm{B}, \mathrm{C})$ are procured from four suppliers (I-IV). The scheme of the supply system of HGDO is shown in Figure 2. The delivery of all purchased products in this macrologistical system is carried out according to the following schemes: suppliers - CW, suppliers - RW, suppliers- LW, CW - RW - LW and RW - LW, taking into account distances between the participants of the procurement process and volumes of transported products.

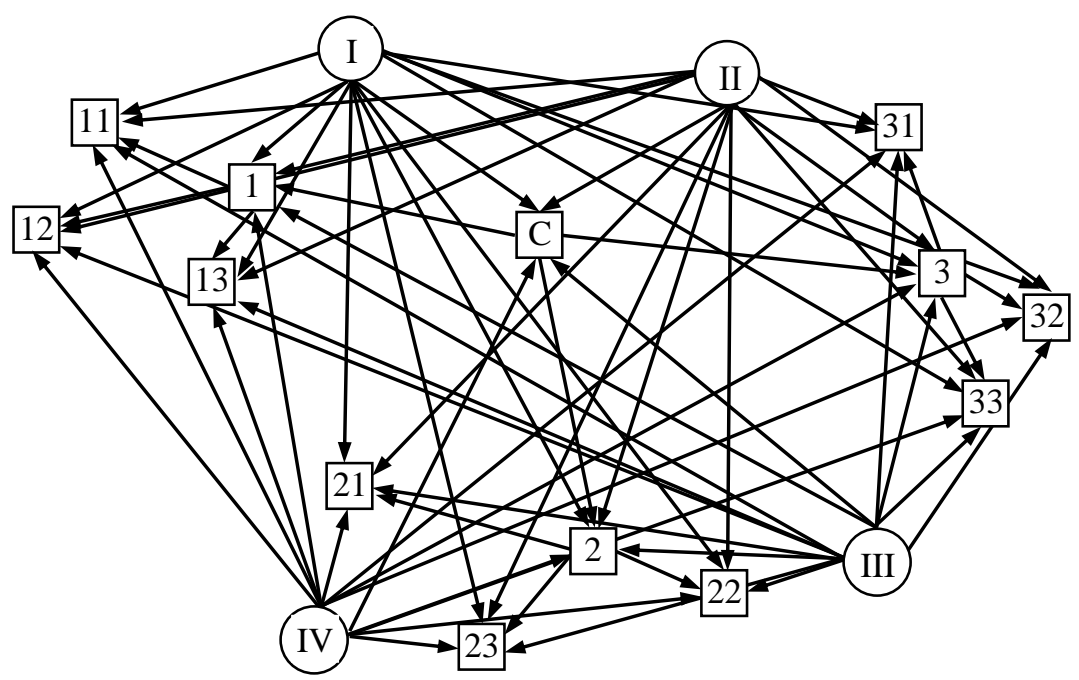

Figure 2. Scheme of the supply system of the investigated HGDO (as an example)

The procurement process is considered for 4 time periods $(\mathrm{t} 1, \mathrm{t} 2, \mathrm{t} 3, \mathrm{t} 4)$.

The initial data for modeling the HGDO procurement process are divided into several groups:

- the needs of TRU, the capabilities of suppliers, the boundary levels of smalland large-scale purchases for different types of products are given in Table 1 : 
Volodymyr Sysoiev, Yuri Kushneruk

Table 1. Data on the needs of TRU and the capabilities of suppliers, unit

\begin{tabular}{|c|c|c|c|c|c|c|c|c|c|c|c|c|c|}
\hline \multirow{2}{*}{$\begin{array}{l}\text { Quantitative } \\
\text { parameters }\end{array}$} & \multirow{2}{*}{$\begin{array}{l}\text { Type of } \\
\text { products } \\
\begin{array}{c}\text { Period of } \\
\text { time }\end{array}\end{array}$} & \multicolumn{4}{|c|}{ A } & \multicolumn{4}{|c|}{ B } & \multicolumn{4}{|c|}{ C } \\
\hline & & $\mathrm{t} 1$ & $\mathrm{t} 2$ & $\mathrm{t} 3$ & $\mathrm{t} 4$ & $\mathrm{t} 1$ & $\mathrm{t} 2$ & $\mathrm{t} 3$ & $\mathrm{t} 4$ & $\mathrm{t} 1$ & $\mathrm{t} 2$ & t3 & $\mathrm{t} 4$ \\
\hline \multirow{9}{*}{$\begin{array}{l}\text { Needs of } \\
\text { TRU }\end{array}$} & 11 & 150 & 170 & 180 & \begin{tabular}{|l|}
165 \\
\end{tabular} & 45 & 46 & \begin{tabular}{|l|}
52 \\
\end{tabular} & 54 & \begin{tabular}{|l|l}
1100 \\
\end{tabular} & 1200 & 1150 & 1200 \\
\hline & 12 & 110 & \begin{tabular}{|l|}
100 \\
\end{tabular} & 110 & \begin{tabular}{|l|}
122 \\
\end{tabular} & 32 & 34 & 36 & 35 & 900 & 950 & 960 & 970 \\
\hline & 13 & 115 & 115 & 105 & 115 & 35 & 38 & 35 & 39 & 1020 & 1010 & 1010 & \begin{tabular}{|l|l|}
1020 \\
\end{tabular} \\
\hline & 21 & 90 & \begin{tabular}{|l|}
93 \\
\end{tabular} & 93 & \begin{tabular}{|l|l}
110 \\
\end{tabular} & 25 & 25 & 28 & 26 & 880 & 900 & 900 & 890 \\
\hline & 22 & 145 & \begin{tabular}{|l|l|}
165 \\
\end{tabular} & 168 & \begin{tabular}{|l|}
173 \\
\end{tabular} & 48 & \begin{tabular}{|l|}
48 \\
\end{tabular} & \begin{tabular}{|l|}
50 \\
\end{tabular} & 54 & 1150 & 1100 & 1150 & 1200 \\
\hline & 23 & 170 & 170 & 170 & \begin{tabular}{|l|}
160 \\
\end{tabular} & 60 & 60 & \begin{tabular}{|l|}
65 \\
\end{tabular} & 64 & 1280 & 1280 & 1340 & 1360 \\
\hline & 31 & 120 & 115 & 115 & \begin{tabular}{|l|}
108 \\
\end{tabular} & 44 & 42 & \begin{tabular}{|l|}
40 \\
\end{tabular} & 43 & 1050 & 1080 & 1060 & 1070 \\
\hline & 32 & 135 & 145 & 140 & \begin{tabular}{|l|}
145 \\
\end{tabular} & 54 & 52 & \begin{tabular}{|l|}
50 \\
\end{tabular} & 52 & 1190 & 1190 & 1210 & 1170 \\
\hline & 33 & 115 & 110 & 120 & \begin{tabular}{|l|}
122 \\
\end{tabular} & 36 & \begin{tabular}{|l|}
39 \\
\end{tabular} & \begin{tabular}{|l|}
34 \\
\end{tabular} & 35 & 1070 & 1000 & 1040 & 1090 \\
\hline \multirow{4}{*}{$\begin{array}{l}\text { Amount of } \\
\text { products } \\
\text { from } \\
\text { suppliers }\end{array}$} & I & 350 & 340 & 360 & 390 & 130 & 120 & \begin{tabular}{|l|}
120 \\
\end{tabular} & 130 & 3600 & 3300 & 3000 & 3100 \\
\hline & II & 340 & 380 & 400 & 350 & 100 & 110 & 110 & 100 & 2900 & 3100 & 3200 & 2500 \\
\hline & III & 240 & 200 & 210 & 210 & 110 & 130 & 100 & 80 & 2000 & 2100 & 2000 & 2400 \\
\hline & IV & 280 & 300 & 300 & 340 & 80 & \begin{tabular}{|l|}
100 \\
\end{tabular} & 130 & 150 & 2200 & 2400 & 2600 & 2800 \\
\hline \multirow{2}{*}{$\begin{array}{l}\text { Levels of } \\
\text { bulk } \\
\text { purchases }\end{array}$} & small & \multicolumn{4}{|c|}{120} & \multicolumn{4}{|c|}{40} & \multicolumn{4}{|c|}{1100} \\
\hline & large & \multicolumn{4}{|c|}{180} & \multicolumn{4}{|c|}{80} & \multicolumn{4}{|c|}{2200} \\
\hline
\end{tabular}

- procurement costs, including the price per unit products for different amount of purchases and costs of placing an order for the purchase different types of products are given in Table 2 :

Table 2. Data on costs for the products purchasing

\begin{tabular}{|c|c|c|c|c|c|c|c|c|c|c|c|c|c|}
\hline \multirow{2}{*}{$\begin{array}{l}\text { Purchase } \\
\text { costs }\end{array}$} & \multirow{2}{*}{$\begin{array}{c}\begin{array}{c}\text { Type of } \\
\text { products }\end{array} \\
\begin{array}{c}\text { Period of } \\
\text { time }\end{array}\end{array}$} & \multicolumn{4}{|c|}{ A } & \multicolumn{4}{|c|}{ B } & \multicolumn{4}{|c|}{$\mathrm{C}$} \\
\hline & & $\mathrm{t} 1$ & $\mathrm{t} 2$ & $\mathrm{t} 3$ & $\mathrm{t} 4$ & $\mathrm{t} 1$ & $\mathrm{t} 2$ & $\mathrm{t} 3$ & $\mathrm{t} 4$ & $\mathrm{t} 1$ & $\mathrm{t} 2$ & $\mathrm{t} 3$ & t4 \\
\hline \multirow{4}{*}{$\begin{array}{l}\text { Price per } \\
\text { unit (small } \\
\text { wholesale), } \\
€\end{array}$} & I & \begin{tabular}{|l|}
98 \\
\end{tabular} & 100 & 102 & \begin{tabular}{|l|}
104 \\
\end{tabular} & 310 & 312 & 314 & 316 & 38 & 38 & 40 & 40 \\
\hline & II & \begin{tabular}{|c|}
100 \\
\end{tabular} & 100 & 103 & \begin{tabular}{|l|l|}
103 \\
\end{tabular} & 314 & 314 & 316 & 316 & 40 & 40 & 43 & 43 \\
\hline & III & 103 & 103 & 103 & 103 & 315 & 315 & 317 & 317 & 39 & 40 & 41 & 42 \\
\hline & IV & 96 & 99 & \begin{tabular}{|l|}
102 \\
\end{tabular} & 105 & 312 & 315 & 318 & 321 & 42 & 42 & 43 & 43 \\
\hline \multirow{2}{*}{$\begin{array}{l}\text { Wholesale } \\
\text { discount, } \\
\%\end{array}$} & $\begin{array}{c}\text { average } \\
\text { wholesale }\end{array}$ & \multicolumn{4}{|c|}{12} & \multicolumn{4}{|c|}{16} & \\
\hline & $\begin{array}{c}\text { large } \\
\text { wholesale }\end{array}$ & \multicolumn{4}{|c|}{18} & \multicolumn{4}{|c|}{22} & \multicolumn{4}{|c|}{15} \\
\hline \multirow{3}{*}{$\begin{array}{l}\text { Costs of } \\
\text { placing an } \\
\text { order, } €\end{array}$} & $\mathrm{CO}$ & \begin{tabular}{|l|}
560 \\
\end{tabular} & 570 & \begin{tabular}{|l|}
580 \\
\end{tabular} & \begin{tabular}{|l}
590 \\
\end{tabular} & 340 & 360 & 370 & 380 & \begin{tabular}{|l|}
760 \\
\end{tabular} & \begin{tabular}{|l|}
780 \\
\end{tabular} & \begin{tabular}{|l|}
790 \\
\end{tabular} & 800 \\
\hline & RR & 540 & 550 & 570 & 580 & 330 & 350 & 360 & 375 & 730 & 750 & 770 & 780 \\
\hline & TRU & 520 & 540 & 560 & 570 & 320 & 330 & 350 & 365 & 700 & 730 & 750 & 77 \\
\hline
\end{tabular}


Supply Optimization Model in the Hierarchical Geographically Distributed Organization

- transportation costs on the delivery of different types of purchased products are given in Table 3:

Table 3. Data on transport costs for the delivery of a unit of products, $€$ / km

\begin{tabular}{|c|c|c|c|c|c|c|c|c|c|}
\hline \multirow{2}{*}{$\begin{array}{c}\text { Distance, } \\
\mathrm{km}\end{array}$} & \multicolumn{9}{|c|}{ Amount of products, unit } \\
\cline { 2 - 10 } & \multicolumn{3}{|c|}{$\mathrm{A}$} & \multicolumn{3}{c|}{$\mathrm{B}$} & \multicolumn{3}{c|}{$\mathrm{C}$} \\
\cline { 2 - 10 } & $<120$ & $120 \div 180$ & $>180$ & $<40$ & $40 \div 60$ & $>60$ & $<1000$ & $1000 \div 1500$ & $>1500$ \\
\hline$<250$ & 0.1 & 0.11 & 0.12 & 0.42 & 0.45 & 0.48 & 0.02 & 0.023 & 0.026 \\
\hline $250 \div 500$ & 0.13 & 0.14 & 0.15 & 0.51 & 0.54 & 0.57 & 0.029 & 0.032 & 0.035 \\
\hline$>500$ & 0.16 & 0.17 & 0.18 & 0.6 & 0.63 & 0.66 & 0.038 & 0.041 & 0.044 \\
\hline
\end{tabular}

- warehousing costs, including the cost of cargo handling and storage of a unit of products, which are calculated as a percentage of its price are given in Table 4:

Table 4. Data on warehouse costs, \% (percentage of the value of products)

\begin{tabular}{|l|c|c|c|c|}
\hline \multirow{2}{*}{ Warehouse costs } & Types of & \multicolumn{3}{|c|}{ Type of products } \\
\cline { 2 - 5 } & warehouses & $\mathrm{A}$ & $\mathrm{B}$ & $\mathrm{C}$ \\
\hline Costs of cargo handling of a unit products in & $\mathrm{CW}$ & 10 & 12 & 8 \\
\cline { 2 - 5 } $\begin{array}{l}\text { warehouses of different levels of the echeloned storage } \\
\text { system }\end{array}$ & $\mathrm{RW}$ & 10 & 12 & 8 \\
\cline { 2 - 5 } & $\mathrm{LW}$ & 4 & 8 & 2 \\
\hline Storage costs for a unit of products in TRU warehouses & LW & 16 & 13 & 10 \\
\hline
\end{tabular}

- the matrix of distances between participants in the HGDO supply process is given in Table 5:

Table 5. Matrix of the distance between participants in the HGDO procurement process, $\mathrm{km}$

\begin{tabular}{|c|c|c|c|c|c|c|c|c|}
\hline & I & II & III & IV & CO & 1 & 2 & 3 \\
\hline I & 0 & - & - & - & 220 & 105 & 500 & 650 \\
\hline II & - & 0 & - & - & 250 & 465 & 490 & 280 \\
\hline III & - & - & 0 & - & 400 & 620 & 275 & 280 \\
\hline IV & - & - & - & 0 & 390 & 330 & 200 & 700 \\
\hline CO & 220 & 250 & 400 & 390 & 0 & 245 & 360 & 450 \\
\hline 1 & 105 & 465 & 620 & 330 & 245 & 0 & - & - \\
\hline 2 & 500 & 490 & 275 & 200 & 360 & - & 0 & - \\
\hline 3 & 650 & 280 & 280 & 700 & 450 & - & - & 0 \\
\hline 11 & 100 & 500 & 700 & 410 & 305 & 80 & - & - \\
\hline 12 & 190 & 585 & 690 & 355 & 365 & 120 & - & - \\
\hline 13 & 150 & 460 & 580 & 280 & 260 & 50 & - & - \\
\hline 21 & 350 & 440 & 375 & 130 & 220 & - & 150 & - \\
\hline 22 & 510 & 410 & 170 & 300 & 310 & - & 110 & - \\
\hline
\end{tabular}


Volodymyr Sysoiev, Yuri Kushneruk

\begin{tabular}{|c|c|c|c|c|c|c|c|c|}
\hline 23 & 460 & 520 & 470 & 120 & 340 & - & 90 & - \\
\hline 31 & 570 & 160 & 360 & 670 & 390 & - & - & 140 \\
\hline 32 & 660 & 280 & 300 & 710 & 500 & - & - & 50 \\
\hline 33 & 640 & 300 & 200 & 620 & 425 & - & - & 80 \\
\hline
\end{tabular}

Suppose that the funds allocated by the organization for purchases are equal to 1.0 million Euros over a period of time.

To implement the proposed optimization model, the "smoothing" algorithm of the Wagner-Whitin supply timetable and the Generalized Reduced Gradient method in Solver Add-In for MS Excel 2010 were used to solve this problem.

The simulation results for this example are shown below.

The ratios of products volumes of each type purchased at different levels of the HGDO hierarchy (CO, RR and TRU) in each period of time are shown in Figure 3.

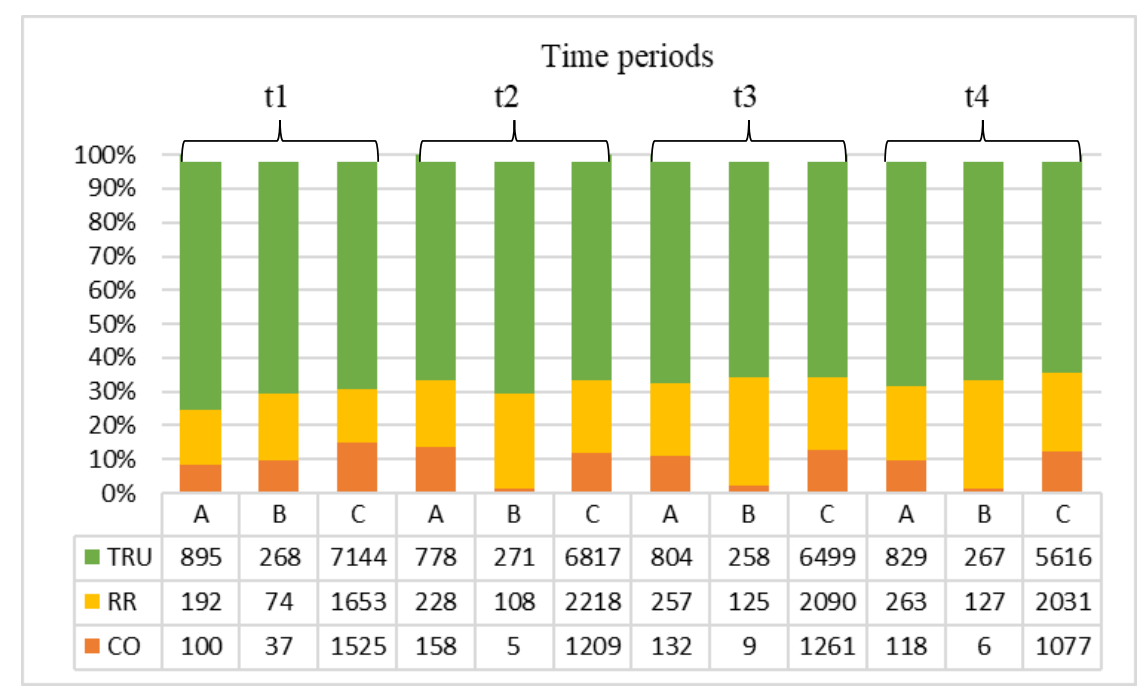

Figure 3. Procurement volumes allocation between HGDO management levels

The volumes of purchases of different types of products from different suppliers in each period of time are shown in Figure 4. 
Supply Optimization Model in the Hierarchical Geographically Distributed Organization

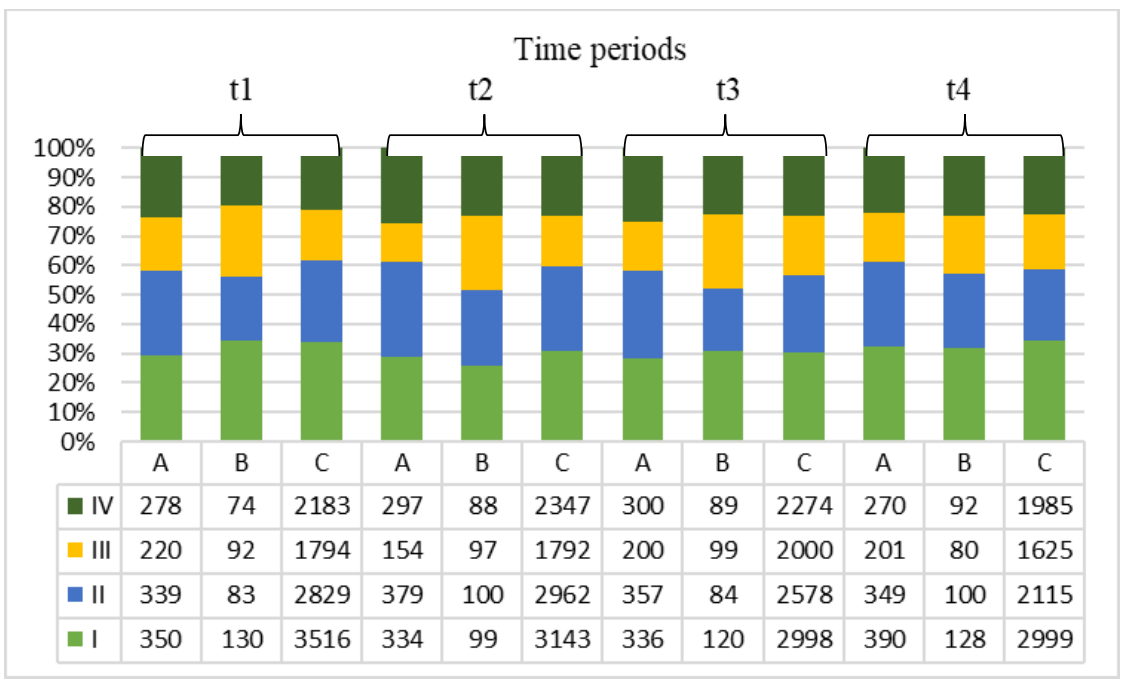

Figure 4. Procurement volumes allocation from different suppliers

In the conditions of the given tendency in the growth of prices for products in each period of time, the purchase of products for the next period at the prices of the current period within the budget of the organization is profitable.

The relationship between the total volume of purchased products of each type and the needs for these products in each period of time are shown in Figure 5.

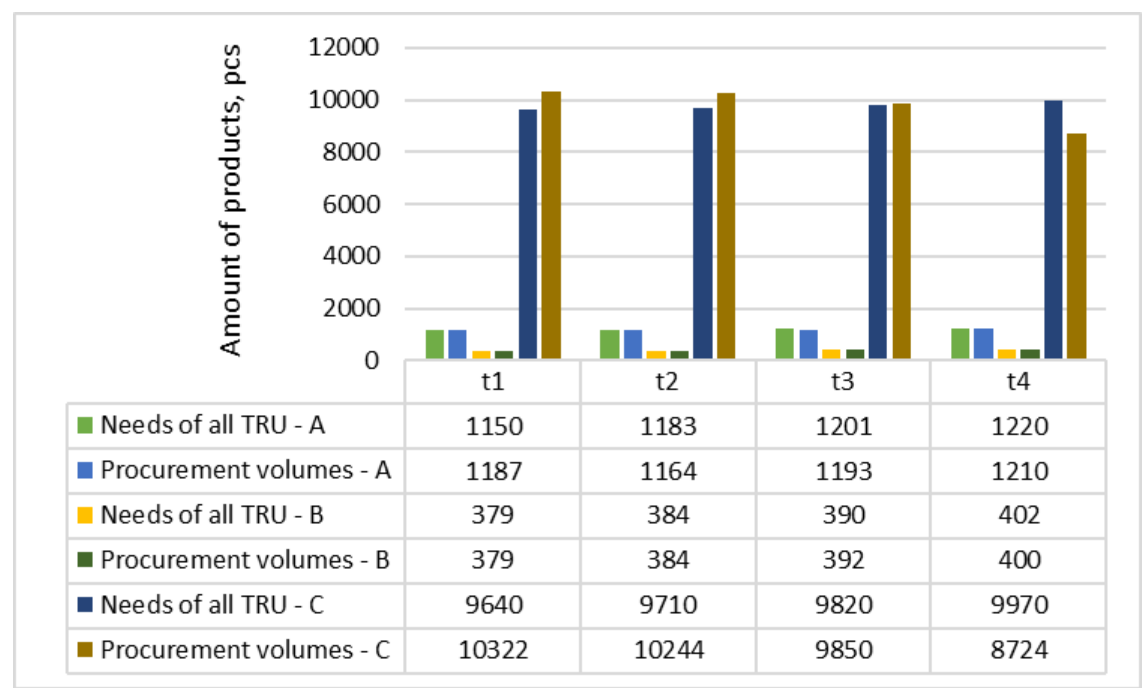

Figure 5. Allocation of shares of products purchased taking into account wholesale discounts in the total volume of purchases 
Volodymyr Sysoiev, Yuri Kushneruk

The dynamics of changes in logistics costs by types of logistics functions implemented in the procurement process of each products type in HGDO is shown in Figure 6.

Modeling the PSM process over time allows using prediction estimates that characterize the trends in various parameters changes describing the participants and logistics functions of the HGDO procurement process. The obtained values of the total logistics costs on each period of time can be considered as approximate data for the budgeting of the HGDO logistic support throughout the planning period.

\section{Conclusions}

Hierarchical geographically distributed organizations, characterized by a vertically integrated branched architecture, have a complex purchasing and supply management system that must balance the corporate synergies and decentralized autonomy of the individual units that comprise it.

In the context of a large number of HGDO structural divisions and suppliers, a wide range of products, purchased products, the dynamics of TRU demands and market conditions that create various options for organizing the procurement process, coordination of PSM at all levels of the hierarchy is necessary to reduce expenses on the HGDO logistic support. 
Supply Optimization Model in the Hierarchical Geographically Distributed Organization

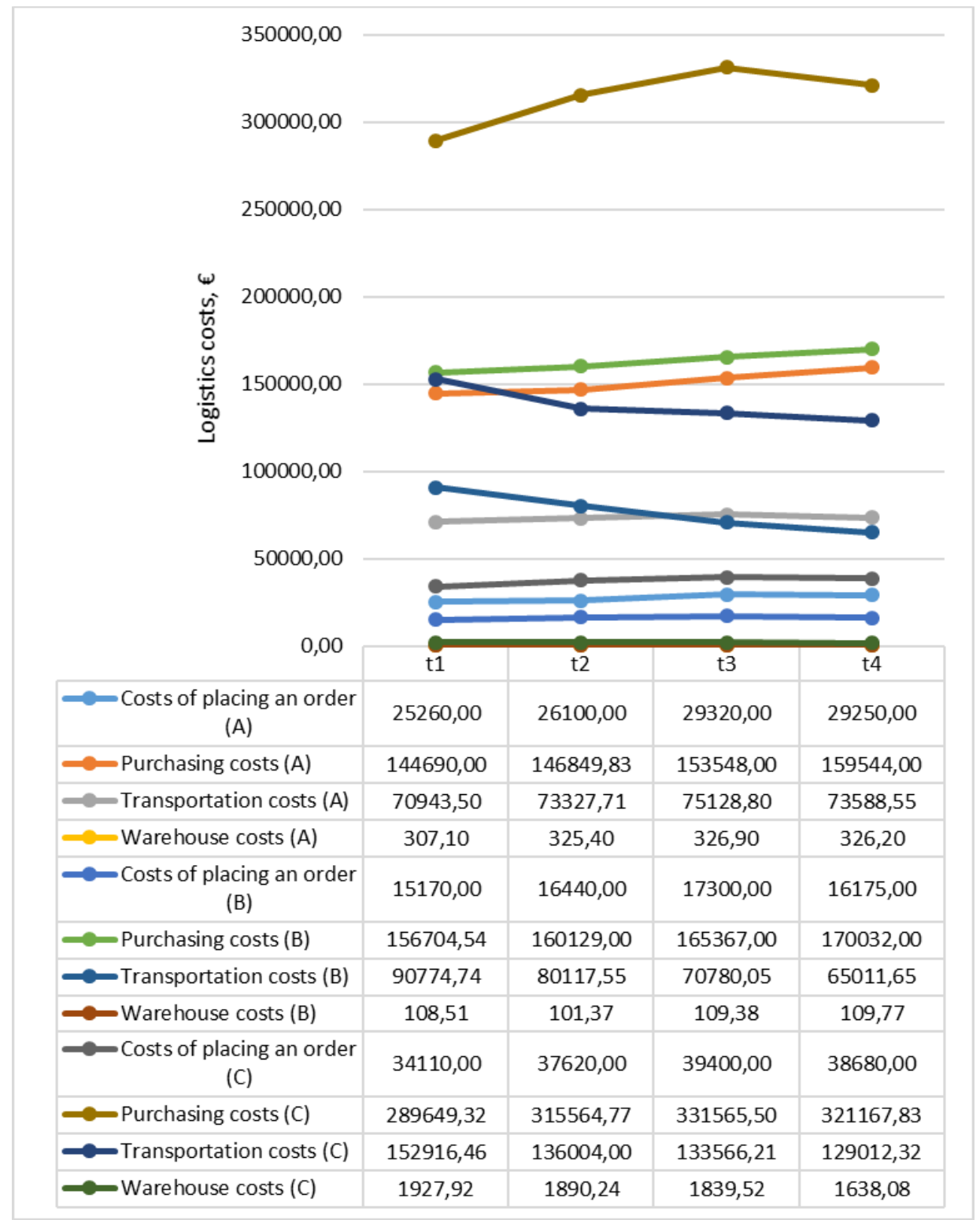

Figure 6. Dynamics of changes in logistics costs that characterize the HGDO procurement process

The proposed model, reflecting the specifics of the organization of a complex, multifactorial and multi-stage procurement process, allows to find the optimal options for purchasing and supplying for the criterion of minimizing the total 
Volodymyr Sysoiev, Yuri Kushneruk

logistics costs characterizing this process for the entire period of logistic support planning through a rational combination of centralized and decentralized management procurement taking into account the values of the various parameters of participants and logistic functions of the procurement process over each time period.

The model is an effective tool for supporting decisions made by HGDO logistics management, which allows to coordinate PSM at different levels of the hierarchy of the organization based on numerous options for purchases and supplying of products and their budgeting in conditions of the dynamics and diversity of internal and external factors of influence.

\section{REFERENCES}

[1] Arlbjørn, J.S., Freytag, P.V. (2012),Public Procurement Vs. Private Purchasing: Is There Any Foundation for Comparing and Learning across the Sectors?;International Journal of Public Sector Management, Vol. 25, No. 3, 203 220;

[2] Baier, C., Hartmann, E. and Moser, R. (2008),Strategic Alignment and Purchasing Efficacy: An Exploratory Analysis of their Impact on Financial Performance;Journal of Supply Chain Management, Vol. 44, No. 4, 36-52;

[3] Balakrishnan, A., Natarajan, H.P. (2014),Integrated Procurement Planning in Multi-Division Firms;Production and Operations Management, Vol. 23, No. 10, 1795-1810;

[4] Giunipero, L.C., Hooker, R.E. and Denslow, D. (2012),Purchasing and Supply Management Sustainability: Drivers and Barriers; Journal of Purchasing and Supply Management, Vol. 18,No. 4, 258-269;

[5] Glock, C.H.,Hochrein, S. (2011),Purchasing Organization and Design: A Literature Review; Business Research, Vol. 4, No. 2, 149-191;

[6] Handfield, R.B., Nichols, E.L. (2004),Key Issues in Global Supply Base Management;Industrial Marketing Management, Vol. 33, No. 1, 29-35;

[7] Hesping, F.H. (2015),Tactics at the Category Level of Purchasing and Supply Management: Sourcing Levers, Contingencies and Performance; Dissertation, University of Twente;

[8] Karjalainen, K. (2011), Estimating the Cost Effects of Purchasing Centralization - Empirical Evidence from Framework Agreements in the Public Sector; Journal of Purchasing and Supply Management, Vol. 17, No. 2, 87-97;

[9] Kleemann, F.S., Glas, A. and Essig, M. (2012), Public Procurement through Performance-based Logistics: Conceptual Underpinnings and Empirical Insights; Journal of Public Procurement, Vol. 12, No. 2, 151-188; 
Supply Optimization Model in the Hierarchical Geographically Distributed Organization

[10] Knoppen, D., Sáenz, M.J. (2015), Purchasing: Can we Bridge the Gap between Strategy and Daily Reality?;Business Horizons, Vol. 58, No. 1, 123-133;

[11] Luzzini, D., Amann, M., Caniato, F., Essig, M. and Ronchi, S. (2015), The Path of Innovation: Purchasing and Supplier Involvement into New Product Development; Industrial Marketing Management, Vol. 47, 109-120;

[12] Matopoulos, A., Bell, J.E. and Aktas E. (2016),The Use of Modelling in Purchasing/Supply Management Research;Journal of Purchasing and Supply Management, Vol. 22,No. 4, 262-265;

[13] Miemczyk, J., Johnsen, T.E. and Macquet, M. (2012),Sustainable Purchasing and Supply Management: A Structured Literature Review of Definitions and Measures at the Dyad, Chain and Network Levels; Supply Chain Management: An International Journal, Vol. 17, No. 5, 478-496;

[14] Munson, C.L. (2007), The Appeal of Partially Centralised Purchasing Policies;International Journal Procurement Management; Vol. 1, No. 1/2, 117143;

[15] Paulraj, A., Chen, I.J. and Flynn, J. (2006),Levels of Strategic Purchasing: Impact on Supply Integration and Performance; Journal of Purchasing and Supply Management, Vol. 12, No. 3,107-122;

[16] Pepino, A., Rovani, M., Torri, A. and Sansone, M. (2012),Supply Chain for Regional Centralized Purchasing: An Application Model; Intelligent Information Management, Vol. 4, No. 5A, 269-276;

[17] Pooler, V.H., Pooler, D.J. and Farney, S.D. (2004),Global Purchasing and Supply Management: Fulfil the Vision; $2^{\text {nd }}$ ed., Kluwer Academic Publishers (Springer), Boston;

[18] Quintens, L., Pauwels, P. and Matthyssens, P. (2006),Global Purchasing: State of the Art and Research Directions; Journal of Purchasing and Supply Management, Vol. 12,No. 4, 170-181;

[19] Rozemeijer, F.A. (2000),Creating Corporate Advantage in Purchasing; Proefschrift, TechnischeUniversiteit Eindhoven, Eindhoven;

[20] Rozemeijer, F.A., Van Weele, A.J. and Weggeman, M. (2003), Creating Corporate Advantage through Purchasing: Toward a Contingency Model;Journal of Supply Chain Management, Vol. 39, No. 4, 4-13;

[21] Saranga, H., Moser, R. (2010),Performance Evaluation of Purchasing and Supply Management Using Value Chain DEA Approach;European Journal of Operational Research, Vol. 207, No. 1, 197-205;

[22] Spina, G., Caniato, F., Luzzini, D. and Ronchi, S. (2013),Past, Present and Future Trends of Purchasing and Supply Management: An Extensive Literature Review;Industrial Marketing Management, Vol. 42, No. 8, 12021212 ; 
Volodymyr Sysoiev, Yuri Kushneruk

[23] Trautmann, G., Bals, L. and Hartmann, E. (2009), Global Sourcing in Integrated Network Structures: The Case of Hybrid Purchasing Organizations; Journal of International Management, Vol. 15, No.2, 194-208;

[24] Vagstad, S. (2000),Centralized vs. Decentralized Procurement: Does Dispersed Information Call for Decentralized Decision-Making? ;International Journal of Industrial Organization, Vol. 18,No. 6, 949-963;

[25]Zheng, J., Knight, L., Harland, C., Humby, S. andJames, K. (2007),An Analysis of Research into the Future of Purchasing and Supply Management;Journal of Purchasing and Supply Management, Vol. 13,No.1, 69-83. 